Research Article

\title{
Preconditioning Contractions Suppress Muscle Pain Markers after Damaging Eccentric Contractions
}

\author{
Hiroshi Nagahisa, ${ }^{1}$ Kazumi Ikezaki, ${ }^{1}$ Ryotaro Yamada, ${ }^{2}$ Takashi Yamada, ${ }^{2}$ \\ and Hirofumi Miyata $\mathbb{C}^{1}$ \\ ${ }^{1}$ Biological Sciences, Graduate School of Sciences and Technology for Innovation, Yamaguchi University, Yoshida 1677-1, \\ Yamaguchi 753-8515, Japan \\ ${ }^{2}$ Graduate School of Health Sciences, Sapporo Medical University, Sapporo 060-8556, Japan \\ Correspondence should be addressed to Hirofumi Miyata; hiro@yamaguchi-u.ac.jp
}

Received 22 May 2018; Revised 20 August 2018; Accepted 18 September 2018; Published 14 October 2018

Academic Editor: Filippo Brighina

Copyright (c) 2018 Hiroshi Nagahisa et al. This is an open access article distributed under the Creative Commons Attribution License, which permits unrestricted use, distribution, and reproduction in any medium, provided the original work is properly cited.

\begin{abstract}
Inexperienced vigorous exercise, including eccentric contraction (ECC), causes muscle pain and damage. Similar prior light exercise suppresses the development of muscle pain (repeated-bout effect), but the molecular mechanisms behind this are not sufficiently understood. In this study, the influence of a nondamaging preconditioning ECC load (Precon) on muscle pain-related molecules and satellite cell-activating factors was investigated at the mRNA expression level. Nine-week-old male Wistar rats $(n=36)$ were divided into 2 groups: a group receiving only a damaging ECC (100 contractions) load (non-Precon) and a group receiving a nondamaging ECC (10 contractions) load 2 days before receiving the damaging ECC load (Precon). ECC was loaded on the left leg, and the right leg was regarded as the intact control (CTL). The medial head of the gastrocnemius muscle from all rats was excised 2 or 4 days after the damaging ECC loading, and the relative mRNA expression levels of muscle pain-and satellite cell-related molecules were quantitated using real-time RT PCR. Precon suppressed increases in MHC-embryonic and MHCneonatal mRNA expressions. Enhancement of HGF, Pax7, MyoD, and myogenin mRNA expression was also suppressed, suggesting that Precon decreased the degree of muscle damage and no muscle regeneration or satellite cell activation occurred. Similarly, increases in mRNA expression of muscle pain-related molecules $\left(\mathrm{BKB}_{2}\right.$ receptor, $\mathrm{COX}-2$, and mPGEC-1) were also suppressed. This study clearly demonstrated that at the mRNA level, prior light ECC suppressed muscle damage induced by later damaging ECC and promoted recovery from muscle pain.
\end{abstract}

\section{Introduction}

Inexperienced vigorous exercise, including eccentric contraction (ECC), induces muscle damage, edema, reduction of tension, limitation of the range of motion, and muscle pain. Regarding muscle pain, delayed onset muscle soreness (DOMS) persists for several days after exercise and generally resolves after several days [1-3]. ECC more effectively promotes muscular hypertrophy compared with concentric and isometric contractions $[4,5]$. Therefore, ECC is considered to be efficient exercise for rehabilitation and training aiming at improvement of muscle function. On the other hand, ECC-induced symptoms, such as DOMS, may influence activity in daily life, rehabilitation, and motivation of athletes for daily training even though the symptoms are transient. However, it is also known that performing similar exercise several days before training reduces the grade of DOMS and damage and promotes recovery of reduced tension $[2,6,7]$. This effect of pre-exercise is referred to as the repeated-bout effect, and it has been reported to appear within 2 days to one week [6-8] and persist for 6 months [9]. However, the physiological mechanisms concerning the effects of pre-exercise on muscle pain and regeneration remain still unclear.

Experimentally, in a model of muscle pain of inflammation induced by formalin injection into the 
gastrocnemius muscle, mRNA expression of the $\mathrm{B}_{2}$ receptor of bradykinin (BK) represents several bioactivities, including induction of increases in muscle pain [10]. As this muscle pain is suppressed by administration of $\mathrm{BKB}_{2}$ receptor antagonist, the $\mathrm{BKB}_{2}$ receptor is considered to be involved in muscle pain $[8,10]$. Other molecules involved in pain include prostaglandin (PG) $\mathrm{E}_{2}$. The protein and mRNA expression levels of an enzyme involved in $\mathrm{PGE}_{2}$ synthesis, cyclooxygenase-2 (COX-2), increase after ECC [11]. Muscle pain and inflammation after ECC and those induced by carrageenan are reduced by administration of a COX-2 inhibitor, and the level of the final product of COX-2, $\mathrm{PGE}_{2}$, simultaneously decreases $[11,12]$. There are several isozymes of PGE synthase, which is the final enzyme of the $\mathrm{PGE}_{2}$ synthetic pathway, and microsomal PGE synthase-1 (mPGES-1) has been suggested to be closely associated with COX-2 [13]. Accordingly, it is likely that expression of COX2 and $\mathrm{mPGES}-1$ in the $\mathrm{PGE}_{2}$ synthetic pathway is involved in muscle pain via $\mathrm{PGE}_{2}$ production.

Although the $\mathrm{BKB}_{2}$ receptor or enzymes in the $\mathrm{PGE}_{2}$ synthetic pathway, such as COX-2 and mPGES-1, may be associated with muscle pain, the influence of pre-exercise on the expression of these muscle pain-related molecules is unclear. In this study, the influence of prior light nondamaging ECC (Precon) on muscle damage, muscle painrelated molecules, and muscle regeneration (satellite cellactivating factors) induced by later damaging ECC was examined at the mRNA expression level.

\section{Materials and Methods}

2.1. Animals and Experimental Protocol. All rat experiments were performed at Yamaguchi University and Sapporo Medical University and conducted in accordance with approved protocols by the Committee on Animal Experiments of Yamaguchi University (No. 290) and Sapporo Medical University (No. 16-077). Animal care was in accordance with institutional guidelines.

Male Wistar rats ( 9 -week old, $n=36$ ) were supplied by Sanyo Labo Service (Sapporo, Japan). Rats were housed in an environmentally controlled room $\left(24 \pm 2^{\circ} \mathrm{C}, 12 \mathrm{~h}: 12 \mathrm{~h}\right.$ lightdark cycle) and given food and water ad libitum. Rats were assigned to a Precon group and a non-Precon group ( $n=18$ in each group). In all the groups, ECC was loaded on the left leg, and the right leg was regarded as intact control (CTL) of each experimental group. In the Precon group, the left plantar flexor muscles were exposed to Precon (i.e., 10 repeated ECC) 2 days prior to 100 repeated damaging ECC. Previous studies showed that muscle damage increase progressively with the number of forced ECC $[14,15]$. In the preliminary experiments, we confirmed that the maximum isometric torque of the plantar flexor muscles was not reduced 48 hours after 10 repeated ECC (data not shown). The left muscles in the non-Precon group were exposed to damaging ECC without Precon. 0 (Immediately), 2, or 4 days after completion of damaging ECC, the planter flexor muscles were removed from each animal $(n=6$ in each group). The medial gastrocnemius muscles were used for further analyses.
2.2. Eccentric Contractions. Under isoflurane anesthesia, rats were placed supine on a platform and their left foot was secured in a foot plate connected to a torque sensor (S14154, Takei Scientific Instruments, Tokyo, Japan) at an angle of $0^{\circ}$ dorsiflexion (i.e., $90^{\circ}$ relative to the tibia). ECC comprised forced dorsiflexion from $0^{\circ}$ to $40^{\circ}$ at $150^{\circ} / \mathrm{s}$ combined with neuromuscular electrical stimulation (ES). Plantar flexor muscles were stimulated supramaximally $(45 \mathrm{~V})$ via a pair of surface electrodes every $4 \mathrm{~s}$. Stimulation parameters were set as follows: $1 \mathrm{~ms}$ monophasic rectangular pulse and $50 \mathrm{~Hz}$ stimulation frequency. The torque production was measured during ES.

2.3. Histochemical Analysis. Cryostat sections (10 $\mu \mathrm{m})$ were stained with hematoxylin and eosin (H\&E). To obtain sections with Evans blue dye (EBD), rats were intraperitoneally injected with $1 \%$ (wt/vol) EBD solution (1 mg/10 g body wt) 24 hours before sacrifice. H\&E and EBD images were obtained from the serial sections using a fluorescence microscope BIOREVO BZ-9000 (KEYENCE, Osaka, Japan).

2.4. Real-Time RT PCR. The procedure described in the previous study was used for real-time RT PCR analysis [16]. The muscle samples were homogenized with TRIzol reagent (Molecular Probes, Breda, Netherlands) to extract total RNA. Genomic DNA was removed from total RNA by treating for $30 \mathrm{~min}$ at $37^{\circ} \mathrm{C}$ with TURBO DNase (Ambion, Austin, USA). To synthesize first strand cDNA, DNasetreated RNA $(0.5 \mu \mathrm{g})$ was used with an Exscript RT reagent kit (Takara, Tokyo, Japan). Subsequently, the SYBR Green PCR Master Mix protocol in the StepOne Plus RealTime PCR system (Applied Biosystems Japan, Tokyo, Japan) was used for real-time PCR analysis of cDNA products.

The amplification program was composed of an initial denaturation step at $95^{\circ}$ for $10 \mathrm{~min}, 40$ cycles of denaturation at $95^{\circ}$ for $30 \mathrm{sec}$, and annealing/extension at $58^{\circ}$ for $1 \mathrm{~min}$. Glyceraldehyde-3-phosphate dehydrogenase (GAPDH) was used to estimate an internal control. The normalization of each mRNA was calculated from GAPDH by subtracting the cycle threshold $\left(C_{t}\right)$ value of GAPDH from the $C_{t}$ value of the target gene $\left(\Delta C_{t}\right.$ (target)). The relative expression of the target gene was calculated as the relative quantification value for the CTL value. No nonspecific amplification in cDNA samples was detected by dissociation curve analysis after the relative expression.

Table 1 shows the sequences of the specific primers used in the present study. Primer Express software (Applied Biosystems Japan) was used for design of each PCR primer. The oligonucleotides were purchased from FASMAC (FASMAC, Kanagawa, Japan).

2.5. Statistical Analyses. All values are expressed as mean \pm standard error (SE). Differences in mRNA expressions between groups were compared using one-way ANOVA followed by $t$-test with Bonferroni adjustment. Statistical significance was set at $P<0.05$. 
TABLE 1: Real-time RT PCR primer sequences.

\begin{tabular}{|c|c|c|c|c|}
\hline Gene & Accession number & & Sequence & Primer position \\
\hline \multirow{2}{*}{ GAPDH } & \multirow{2}{*}{ NM_017008.4 } & Forward & GCTCTCTGCTCCTCCCTGTTC & $4-24$ \\
\hline & & Reverse & GAGGCTGGCACTGCACAA & $44-61$ \\
\hline \multirow{2}{*}{ MHC-embryonic } & \multirow{2}{*}{ NM_012604.1 } & Forward & CTTCAAACTGAAAAACGCCTATGA & $4536-4559$ \\
\hline & & Reverse & GTTCTAAGTTCTTATTCTCTCGCTTCACA & $4584-4612$ \\
\hline \multirow{2}{*}{ MHC-neonatal } & \multirow{2}{*}{ NM_001100485.1 } & Forward & ATCAGTGCCAATCCCTTGCT & $742-761$ \\
\hline & & Reverse & CCAAAGCGAGGAGTTGTCA & $795-815$ \\
\hline \multirow{2}{*}{ HGF } & \multirow{2}{*}{ NM_017017.2 } & Forward & AAAACTACATGGGCAACTTATCCAA & $1335-1359$ \\
\hline & & Reverse & ATGACGGTGTAAATCCTCCATATTC & $1396-1420$ \\
\hline \multirow{2}{*}{ Pax7 } & \multirow{2}{*}{ NM_001191984.1 } & Forward & AAAAGATTGAGGAGTATAAGAGGGAGAA & $347-374$ \\
\hline & & Reverse & GCCGGTCCCGGATTTC & $394-409$ \\
\hline \multirow{2}{*}{ MyoD } & \multirow{2}{*}{ NM_176079.1 } & Forward & GACGGCTCTCTCTGCTCСTTT & $259-279$ \\
\hline & & Reverse & AGTCGAAACACGGATCATCATAGA & $296-319$ \\
\hline \multirow{2}{*}{ Myogenin } & \multirow{2}{*}{ M24393.1 } & Forward & GACCCTACAGGTGCCCACAA & $604-623$ \\
\hline & & Reverse & CCGTGATGCTGTCCACGAT & $643-661$ \\
\hline \multirow{2}{*}{$\mathrm{BKB}_{2}$ receptor } & \multirow{2}{*}{ M59967.2 } & Forward & GAGCTTGAAGCATCCTAGGGAAT & $1543-1565$ \\
\hline & & Reverse & CGCTTATGCCGTGAGACAAGA & $1583-1603$ \\
\hline \multirow{2}{*}{ COX-2 } & \multirow{2}{*}{ U03389.1 } & Forward & GGCAAAGGCCTCCATTGAC & $1423-1441$ \\
\hline & & Reverse & GCGTTTGCGGTACTCATTGA & $1470-1489$ \\
\hline \multirow{2}{*}{ mPGES-1 } & \multirow{2}{*}{ NM_021583.3 } & Forward & TGCTCCCCGCCTTTCTG & $78-94$ \\
\hline & & Reverse & CCACCGCGTACATCTTGATG & $115-134$ \\
\hline
\end{tabular}

GAPDH, glyceraldehydes-3-phosphate dehydrogenase; MHC, myosin heavy chain; HGF, hepatocyte growth factor; Pax7, paired box transcription factor-7; MyoD, myogenic determination factor; $\mathrm{BKB}_{2}$, bradykinin $\mathrm{B}_{2}$ receptor; COX-2, cyclooxygenase 2; mPGES-1, microsomal prostaglandin $\mathrm{E}$ synthase-1.

\section{Results}

3.1. Histochemical Properties of Skeletal Muscle after Damaging ECC. There was not obvious histopathological alteration in sections of $\mathrm{H} \& \mathrm{E}$ at 0 day between non-Precon and Precon groups (Figures 1(a) and 1(b)). In sections of $\mathrm{H} \& \mathrm{E}$ at 2 and 4 days after damaging ECC, a number of swollen myofibers with rounded shape and many inflammatory cells surrounding them were observed in the non-Precon group (Figures 1(c) and 1(e)), while these unfavorable changes dramatically were suppressed in the Precon group (Figures 1(d) and 1(f)).

In agreement with these results, EBD-positive fibers which indicate development of membrane damage were not observed in 0 day (Figures $1(\mathrm{~g})$ and $1(\mathrm{~h})$ ), increased at 2 and 4 days after damaging ECC in the non-Precon group (Figures 1(i) and 1(k)), and little increased during the same period in the Precon group (Figures 1(j) and 1(l)).

3.2. Expression of Skeletal Muscle Damage-and RegenerationRelated Factors $m R N A$. The expression level was presented as a value relative to that in CTL muscles of each group at 0 day. MHC-embryonic and MHC-neonatal are expressed during the regeneration process after muscle damage. At 2 days after damaging ECC, the expression level of MHCembryonic mRNA was significantly increased in the Precon group (Figure 2(a)). At 4 days after damaging ECC, both the non-Precon and Precon groups showed significant increase in MHC-embryonic mRNA expression, whereas the expression of MHC-embryonic in the nonPrecon group was significantly greater than in the Precon group.
The expression level of MHC-neonatal, at 0, 2, and 4 days after damaging ECC, was significantly increased in both the non-Precon and Precon groups (Figure 2(b)). However, there was no difference between the non-Precon and Precon groups.

The expression level of HGF mRNA, which is a wellstudied activation factor for satellite cells, was significantly increased in the Precon group at 2 and 4 days after damaging ECC (Figure 3(a)). In the non-Precon group, the mRNA expression of HGF was significantly increased at 2 and 4 days after damaging ECC. However, at 2 and 4 days after damaging ECC, the expression level of HGF mRNA was significantly lower in the Precon group compared with the non-Precon group.

The mRNA expression level of Pax7, which is expressed in activation and proliferation state of satellite cells, was significantly increased only in the nonPrecon group at 2 and 4 days after damaging ECC (Figure 3(b)). In addition, at 4 days after damaging ECC, the expression of Pax7 mRNA was significantly lower in the Precon group compared with nonPrecon group.

The mRNA expression level of MyoD regulating proliferation and differentiation of satellite cells was significantly increased in the non-Precon group 2 days after damaging ECC (Figure 3(c)). At 4 days after damaging ECC, the expression level of MyoD mRNA in the Precon group was significantly lower than in the non-Precon group.

The mRNA expression level of myogenin, which is expressed in the differentiation state of satellite cells, was significantly increased in the Precon group at 0 and 2 days after damaging ECC (Figure 3(d)). In the non-Precon group, at 2 and 4 days after damaging ECC, the mRNA expression level of myogenin was significantly increased. Furthermore, the expression level of myogenin mRNA was significantly 

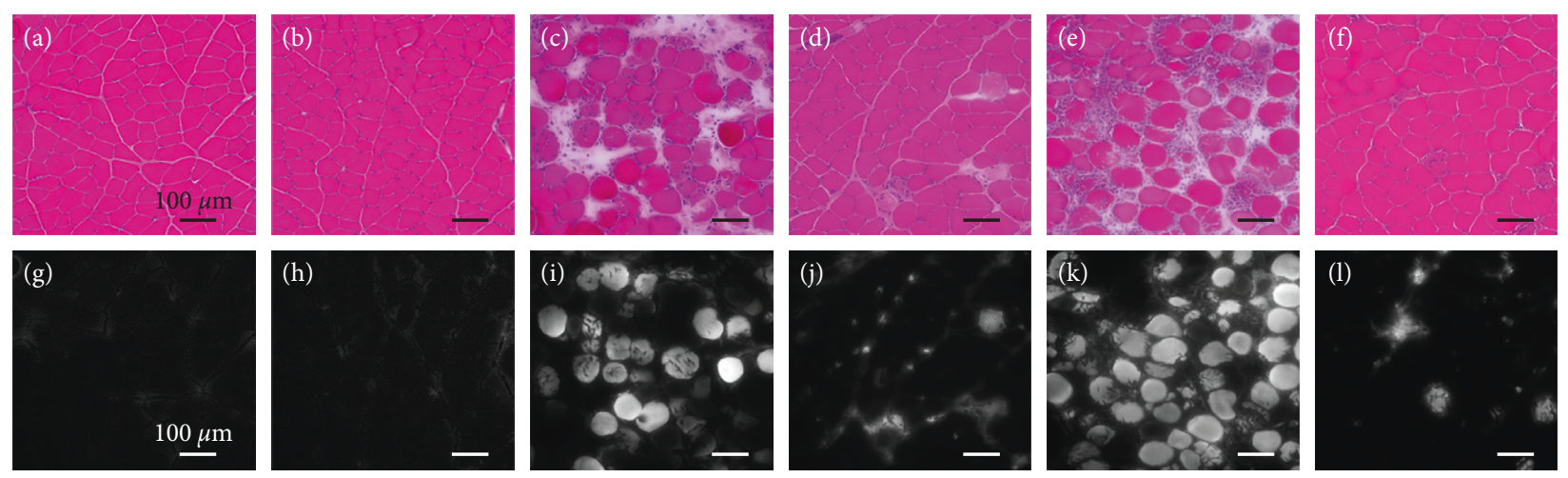

Nonprecon

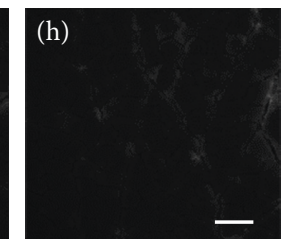

Precon

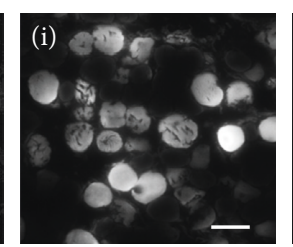

Nonprecon

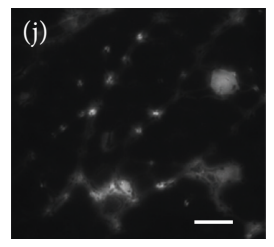

Precon

$2 \mathrm{~d}$

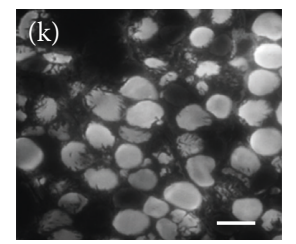

Nonprecon

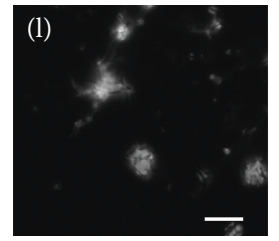

Precon
$0 \mathrm{~d}$

FIGURE 1: Photomicrograph of hematoxylin and eosin (a-f) and Evans blue dye (g-l) staining on sections of the left medial gastrocnemius muscles after damaging eccentric contractions.

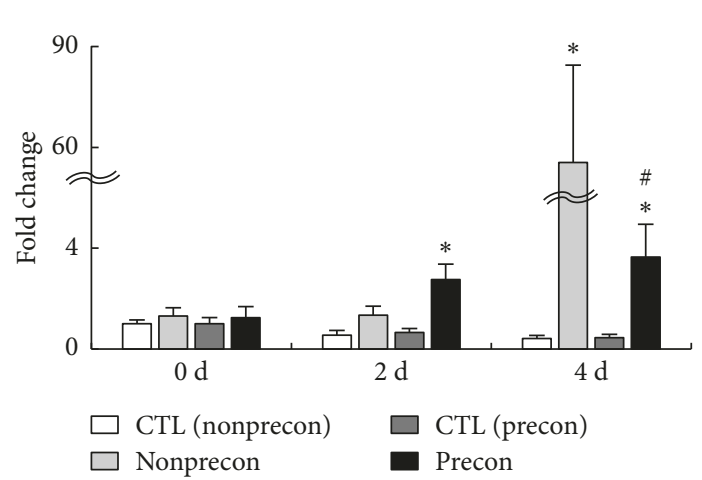

(a)

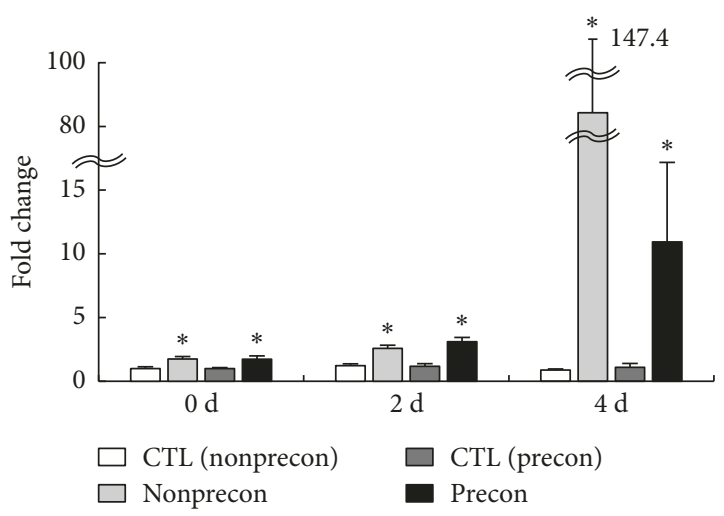

(b)

FIGURE 2: Time course changes in relative expression of MHC-embryonic (a) and MHC-neonatal (b) mRNA. The mRNA expression of each time point was calculated as $\mathrm{x}$-fold change from each CTL value at $0 \mathrm{~d}$. CTL indicates intact right muscle of each experimental group. Values are means \pm SE. ${ }^{*}$ significant differences $(P<0.05)$ as compared with each CTL value. ${ }^{\#}$ significant differences $(P<0.05)$ as compared with each non-Precon value.

lower in the Precon group compared with non-Precon group at 2 and 4 days after damaging ECC.

3.3. The Expression of Muscle Pain-Related Molecules mRNA. The expression level of $\mathrm{BKB}_{2}$ receptor mRNA in the Precon group was significantly increased at 0,2 , and 4 days after damaging ECC (Figure 4(a)). In the non-Precon group, the mRNA expression of $\mathrm{BKB}_{2}$ receptor was significantly increased at 2 and 4 days after damaging ECC. However, at 2 and 4 days after damaging ECC, the expression level of $\mathrm{BKB}_{2}$ receptor mRNA was significantly lower in the Precon group compared with the non-Precon group.

The mRNA expression level of COX-2 in the Precon and non-Precon group was significantly increased at 2 days after damaging ECC (Figure 4(b)). However, at 4 days after damaging ECC, the expression of COX-2 was significantly increased only in the non-Precon group and its expression in the Precon group was significantly lower than in the nonPrecon group.
The expression level of mPGES-1 in the non-Precon group was significantly increased at 2 and 4 days after damaging ECC, whereas there was no marked alteration in the Precon group (Figure 4(c)). In addition, at 4 days after damaging ECC, the expression level of mPGES-1 mRNA was significantly lower in the Precon group compared with the non-Precon group.

\section{Discussion}

The influence of prior light nondamaging ECC on muscle damage, muscle pain, and muscle regeneration-related molecules induced by later damaging ECC was investigated. In fact, Precon suppressed histopathological alteration induced by damaging ECC, corresponding to our previous results [17]. Furthermore, Precon suppressed increases in MHC-embryonic and MHC-neonatal mRNA expressions, suggesting a decrease in the degree of muscle damage. Similarly, increases in mRNA expression of HGF, Pax7, MyoD, and myogenin were suppressed by Precon, 


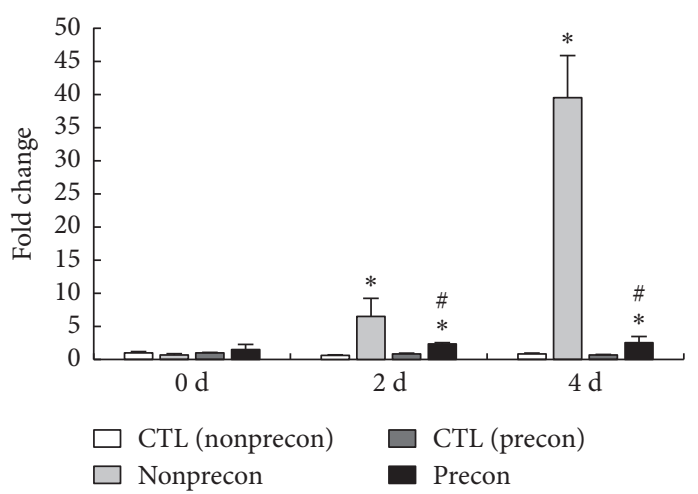

(a)

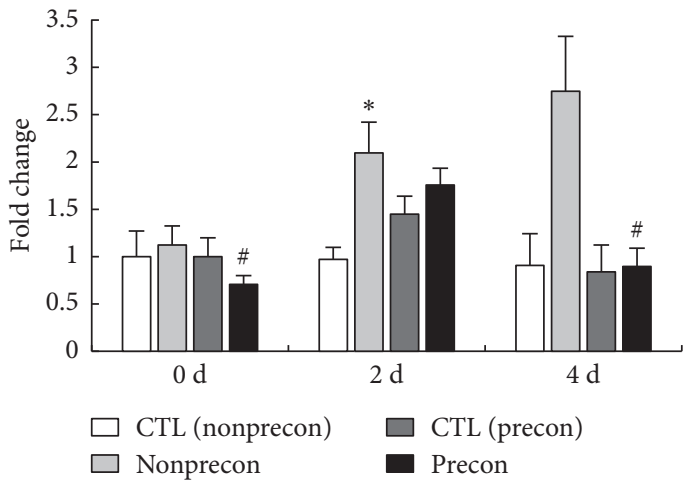

(c)

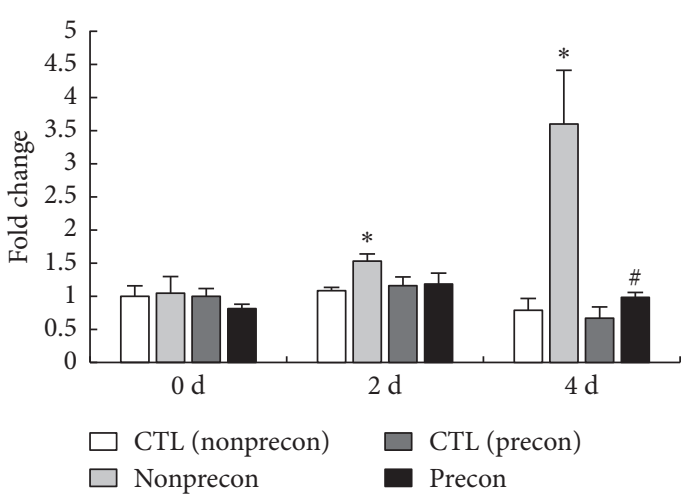

(b)

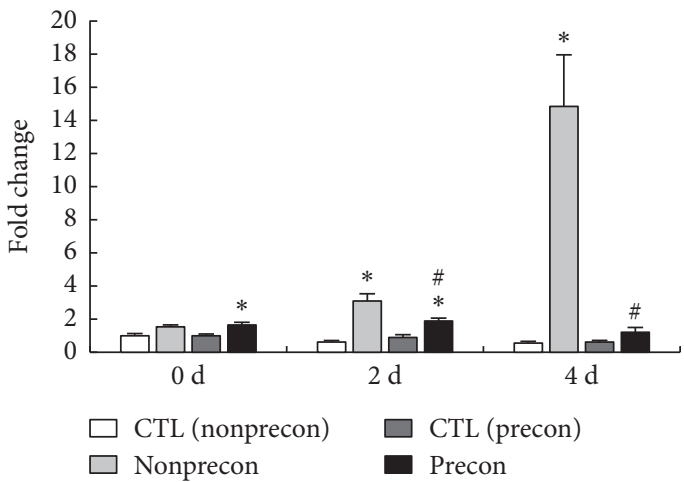

(d)

FIgURE 3: Time course changes in relative expression of HGF (a), Pax7 (b), MyoD (c), and myogenin (d) mRNA. The mRNA expression of each time point was calculated as $\mathrm{x}$-fold change from each CTL value at $0 \mathrm{~d}$. CTL indicates intact right muscle of each experimental group. Values are means \pm SE. ${ }^{*}$ significant differences $(P<0.05)$ as compared with each CTL value. ${ }^{\#}$ significant differences $(P<0.05)$ as compared with each non-Precon value.

suggesting that Precon reduced the degree of muscle damage, negating the need for muscle regeneration. Enhancement of mRNA expression of muscle pain-related molecules was also suppressed. This study demonstrated that prior light ECC reduces muscle damage induced by later damaging ECC and promotes recovery from muscle pain at the mRNA level.

In this study, we did not confirm the effect of Precon itself on mRNA expression. However, most of the mRNA expressions including muscle pain-related molecules in the non-Precon group did not significantly increase compared with its control and Precon groups at 0 day (2 days after Precon). Considering that the Precon itself (10 repeated ECC) has less impact than non-Precon (100 repeated ECC), the effect of Precon itself on mRNA expression was speculated to be little at least 0 and 2 days after the Precon.

4.1. Muscle Damage and Regeneration Induced by Eccentric Contraction. Skeletal muscle expresses developmental MHC, such as MHC-embryonic and MHC-neonatal, in the recovery course after muscle damage, in addition to mature MHC, such as MHC I, IIa, IIx, and IIb [18, 19]. These developmental MHCs are replaced by mature MHC during recovery after muscle damage. MHC-embryonic and MHC-neonatal mRNA expression increased after damaging ECC, but the degree of the increase in MHC-embryonic at 4 days after damaging ECC was reduced by Precon. Muscle satellite cells play an important role in muscle regeneration after muscle damage. Satellite cells are localized between the basement and plasma membranes, but they are normally in the resting state and express Pax7 [20]. When satellite cells are stimulated by muscle damage, they are activated, and they proliferate, differentiate, and supply new muscle fiber and nuclei [20]. Some cells then return to the resting state [20]. Many studies have demonstrated that growth factors such as HGF are associated with activation and proliferation of myoblasts [21]. Furthermore, MyoD and myogenin are expressed when satellite cells are activated, and they proliferate, or differentiate [20]. In the rats that received only damaging ECC, HGF, Pax7, MyoD, and myogenin mRNA expression increased after damaging ECC, suggesting a functional muscle regeneration mechanism, whereas these increases were not observed in the Precon group, suggesting that prior Precon reduced the degree of muscle damage, leading to only a slight need for muscle regeneration. Damage by vigorous ECC has been clarified by indirect analysis (serum creatine kinase) $[1,2]$ and histological analysis [22-24]. In our study, the muscle was 


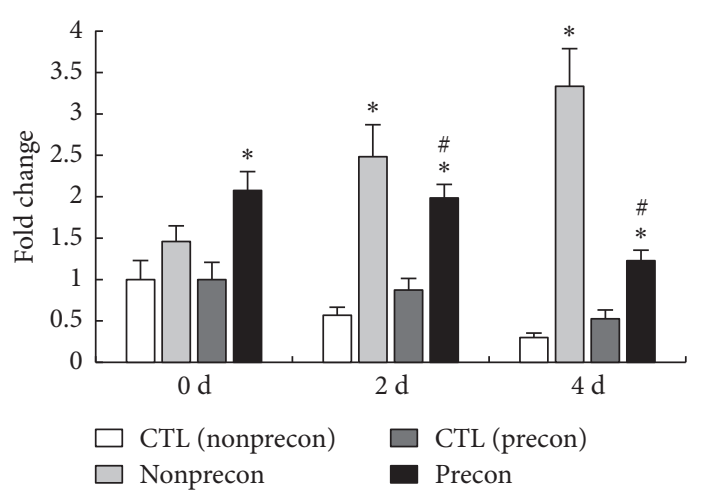

(a)

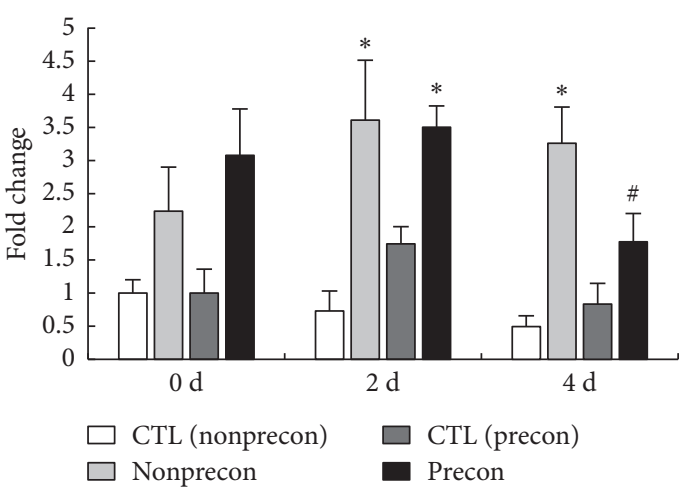

(b)

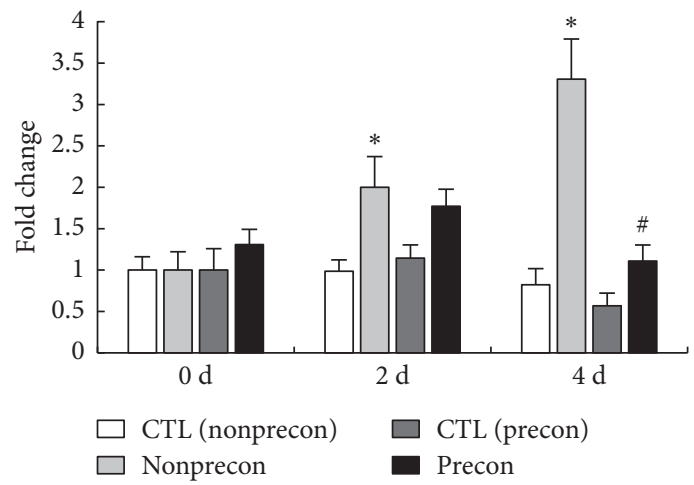

(c)

FIgURE 4: Time course changes in relative expression of $\mathrm{BKB}_{2}$ receptor (a), COX-2 (b), and mPGES-1 (c) mRNA. The mRNA expression of each time point was calculated as $\mathrm{x}$-fold change from each CTL value at $0 \mathrm{~d}$. CTL indicates intact right muscle of each experimental group. Values are means \pm SE. * significant differences $(P<0.05)$ as compared with each CTL value. " significant differences $(P<0.05)$ as compared with each non-Precon value.

damaged in the group only with damaging ECC, confirming that Precon markedly reduced the degree of damage at the mRNA expression level.

\subsection{Muscle Pain Markers Induced by Eccentric Contraction.} $\mathrm{PGE}_{2}$ increases in skeletal muscle during dynamic exercise, but it does not increase during static exercise [25]. An enzyme in the $\mathrm{PGE}_{2}$ synthetic pathway, COX-2, is highly involved in muscle pain. In fact, COX-2 inhibitors can reduce muscle pain when it is applied before lengthening contraction $[11,12]$. In addition, the final enzyme of $\mathrm{PGE}_{2}$ synthesis, mPGES-1, also produces $\mathrm{PGE}_{2}$ from COX-2derived metabolites [13] and is also involved in $\mathrm{PGE}_{2}$-induced pain and inflammation [26]. Therefore, COX-2 and mPGES-1 may induce muscle pain through $\mathrm{PGE}_{2}$ production. In inflammation, COX-2 is expressed in neutrophils, macrophages, endothelial cells, and muscle nuclei/muscle satellite cells $[11,27,28]$. mPGES-1 has been reported to be localized in macrophages and fibroblasts during inflammation $[29,30]$. In the present study, Precon suppressed COX-2 and mPGES-1 mRNA expression, indicating decreased PGE2 production. Accordingly, muscle pain due to $\mathrm{PGE}_{2}$ may have been reduced in the Precon group compared with in the non-Precon group.
Eccentric exercise elevates the blood [31] and interstitial $B K$ levels in skeletal muscle and tendon tissue [32]. There are 2 types of $\mathrm{BK}$ receptors: $\mathrm{BKB}_{1}$ and $\mathrm{BKB}_{2}$. The $\mathrm{BKB}_{1}$ receptor is expressed when tissue is damaged and contributes to chronic inflammation, whereas the $\mathrm{BKB}_{2}$ receptor is constantly expressed and considered to be involved in acute inflammation [33-35]. $\mathrm{BKB}_{2}$ receptor mRNA expression was decreased by Precon 2 and 4 days after damaging ECC. In a previous study, muscle pain developed in the intact leg from 1 to 4 days after eccentric contraction, but when a $\mathrm{BKB}_{2}$ receptor antagonist was administered before eccentric contraction, later muscle pain was suppressed, whereas the $\mathrm{BKB}_{1}$ receptor antagonist exerted no muscle pain-inhibitory effects [36]. In an inflammation model induced by intramuscular injection of formalin, both $\mathrm{BKB}_{1}$ and $\mathrm{B}_{2}$ receptor antagonists demonstrated muscle pain-inhibitory effects from immediately after formalin injection to 7 hours later, but only the $B_{2}$ receptor antagonist reduced IL- 6 mRNA expression [10]. IL-6 is an inflammatory marker that has been suggested to contribute to muscle pain $[37,38]$. Thus, the $\mathrm{BKB}_{2}$ receptor may be more closely involved in muscle pain from inflammation compared with the $B_{1}$ receptor. In addition, administration of a $\mathrm{BKB}_{2}$ receptor antagonist 30 minutes after ECC did not suppress muscle pain, suggesting that the $\mathrm{BKB}_{2}$ receptor functions in the 
development of muscle pain rather than the maintenance of muscle pain [36]. In this study, BKB2 receptor mRNA expression showed significant increase at 0 day (immediately after damaging ECC). However, BKB2 receptor mRNA expression of the non-Precon group gradually increased while those of the Precon group showed gradual decrease, suggesting that the peak of pain marker shifted to the left in the Precon group. Although we could not prove whether the peak shift of $\mathrm{BKB} 2$ receptor $\mathrm{mRNA}$ expression directly relate to muscle pain, the mRNA expression of the Precon group was suppressed in accordance with other muscle painrelated molecules and histopathological damage at 2 and 4 days after damaging ECC.

In summary, we found that the BKB2 receptor which plays an important role in muscle pain significantly increased after eccentric contraction and the expression of mRNA was suppressed by prior low-load ECC in relatively early stage.

\subsection{Influence of Preconditioning on Training Effect. ECC- and} pre-exercise-induced muscle damage, muscle regeneration, and muscle pain were investigated. Our results suggest that prior light ECC reduces muscle damage caused by later damaging ECC and accompanying muscle regeneration and suppresses muscle pain at the mRNA expression level. Based on these findings, in order to reduce exercise-induced muscle pain, prior light exercise may be preferable. However, to improve muscle function, prior light exercise may reduce the later training effects because Precon suppressed mRNA expression of a muscle satellite cell marker, Pax7, which plays an important role in muscular hypertrophy, as well as MyoD and myogenin, which are involved in proliferation and differentiation of satellite cells [20]. In addition, the importance of COX-2 for muscular hypertrophy has been reported using a compensatory muscular hypertrophy model with a COX-2 inhibitor [28]. Thus, suppression of COX-2 expression and activity may be a good method to reduce muscle pain, but COX-2 expression and activity may be necessary when the objective is muscular hypertrophy. Further studies on the long-term effects are necessary.

\section{Data Availability}

The data used to support the findings of this study are available from the corresponding author upon request.

\section{Conflicts of Interest}

The authors declare that they have no conflicts of interest.

\section{Acknowledgments}

This work was supported in part by a grant from the Japanese Ministry of Education, Science and Culture (Nos. 17J08086 and 16H03221).

\section{References}

[1] N. Nelson, "Delayed onset muscle soreness: is massage effective?," Journal of Bodywork and Movement Therapies, vol. 17, no. 4, pp. 475-482, 2013.

[2] T. C. Chen, H. L. Chen, A. J. Pearce, and K. Nosaka, "Attenuation of eccentric exercise-induced muscle damage by preconditioning exercises," Medicine \& Science in Sports \& Exercise, vol. 44, no. 11, pp. 2090-2098, 2012.

[3] R. D. Hyldahl and M. J. Hubal, "Lengthening our perspective: morphological, cellular, and molecular responses to eccentric exercise," Muscle \& Nerve, vol. 49, no. 2, pp. 155-170, 2014.

[4] M. Roig, K. O’Brien, G. Kirk et al., “The effects of eccentric versus concentric resistance training on muscle strength and mass in healthy adults: a systematic review with meta-analysis," British Journal of Sports Medicine, vol. 43, no. 8, pp. 556-568, 2009.

[5] N. Hedayatpour and D. Falla, "Physiological and neural adaptations to eccentric exercise: mechanisms and considerations for training," BioMed Research International, vol. 2015, Article ID 193741, 7 pages, 2015.

[6] A. P. Lavender and K. Nosaka, "A light load eccentric exercise confers protection against a subsequent bout of more demanding eccentric exercise," Journal of Science and Medicine in Sport, vol. 11, no. 3, pp. 291-298, 2008.

[7] S. Maeo, M. Yamamoto, H. Kanehisa, and K. Nosaka, "Prevention of downhill walking-induced muscle damage by non-damaging downhill walking," PLoS One, vol. 12, no. 3, Article ID e0173909, 2017.

[8] H. Urai, S. Murase, and K. Mizumura, "Decreased nerve growth factor upregulation is a mechanism for reduced mechanical hyperalgesia after the second bout of exercise in rats," Scandinavian Journal of Medicine \& Science in Sports, vol. 23, no. 2, pp. e96-e101, 2013.

[9] K. Nosaka, K. Sakamoto, M. Newton, and P. Sacco, "How long does the protective effect on eccentric exercise-induced muscle damage last?," Medicine \& Science in Sports \& Exercise, vol. 33, no. 9, pp. 1490-1495, 2001.

[10] F. C. Meotti, R. Campos, K. da Silva, A. F. Paszcuk, R. Costa, and J. B. Calixto, "Inflammatory muscle pain is dependent on the activation of kinin $B_{1}$ and $B_{2}$ receptors and intracellular kinase pathways," British Journal of Pharmacology, vol. 166, no. 3, pp. 1127-1139, 2012.

[11] S. Murase, E. Terazawa, K. Hirate et al., "Upregulated glial cell line-derived neurotrophic factor through cyclooxygenase-2 activation in the muscle is required for mechanical hyperalgesia after exercise in rats," Journal of Physiology, vol. 591, no. 12, pp. 3035-3048, 2013.

[12] Y. Zhang, A. Shaffer, J. Portanova, K. Seibert, and P. C. Isakson, "Inhibition of cyclooxygenase-2 rapidly reverses inflammatory hyperalgesia and prostaglandin E2 production," Journal of Pharmacology and Experimental Therapeutics, vol. 283, no. 3, pp. 1069-1075, 1997.

[13] B. Samuelsson, R. Morgenstern, and P. J. Jakobsson, "Membrane prostaglandin E synthase-1: a novel therapeutic target," Pharmacological Reviews, vol. 59, no. 3, pp. 207-224, 2007.

[14] M. K. Hesselink, H. Kuipers, P. Geurten, and H. Van Straaten, "Structural muscle damage and muscle strength after incremental number of isometric and forced lengthening contractions," Journal of Muscle Research \& Cell Motility, vol. 17, no. 3, pp. 335-341, 1996.

[15] M. E. Willems and W. T. Stauber, "The effect of number of lengthening contractions on rat isometric force production at 
different frequencies of nerve stimulation," Acta Physiologica, vol. 196, no. 3, pp. 351-356, 2009.

[16] H. Nagahisa, K. Okabe, Y. Iuchi, J. Fujii, and H. Miyata, "Characteristics of skeletal muscle fibers of SOD1 knockout mice," Oxidative Medicine and Cellular Longevity, vol. 2016, Article ID 9345970, 8 pages, 2016.

[17] R. Yamada, K. Himori, D. Tatebayashi et al., "Preconditioning contractions prevent the delayed onset of myofibrillar dysfunction after damaging eccentric contractions," Journal of Physiology, vol. 596, no. 18, pp. 4427-4442, 2018.

[18] S. Schiaffino, A. C. Rossi, V. Smerdu, L. A. Leinwand, and C. Reggiani, "Developmental myosins: expression patterns and functional significance," Skeletal Muscle, vol. 5, p. 22, 2015.

[19] S. Ciciliot and S. Schiaffino, "Regeneration of mammalian skeletal muscle. Basic mechanisms and clinical implications," Current Pharmaceutical Design, vol. 16, no. 8, pp. 906-914, 2010.

[20] N. A. Dumont, Y. X. Wang, and M. A. Rudnicki, "Intrinsic and extrinsic mechanisms regulating satellite cell function," Development, vol. 142, no. 9, pp. 1572-1581, 2015.

[21] M. Yamada, R. Tatsumi, K. Yamanouchi et al., "High concentrations of HGF inhibit skeletal muscle satellite cell proliferation in vitro by inducing expression of myostatin: a possible mechanism for reestablishing satellite cell quiescence in vivo," American Journal of Physiology-Cell Physiology, vol. 298, no. 3, pp. C465-C476, 2010.

[22] Y. Kano, K. Masuda, H. Furukawa, M. Sudo, K. Mito, and K. Sakamoto, "Histological skeletal muscle damage and surface EMG relationships following eccentric contractions," Journal of Physiological Sciences, vol. 58, no. 5, pp. 349-355, 2008.

[23] M. Sudo and Y. Kano, "Myofiber apoptosis occurs in the inflammation and regeneration phase following eccentric contractions in rats," Journal of Physiological Sciences, vol. 59, no. 6, pp. 405-412, 2009.

[24] R. D. Hyldahl, T. Olson, T. Welling, L. Groscost, and A. C. Parcell, "Satellite cell activity is differentially affected by contraction mode in human muscle following a workmatched bout of exercise," Frontiers in Physiology, vol. 5, p. $485,2014$.

[25] M. Karamouzis, H. Langberg, D. Skovgaard, J. Bulow, M. Kjaer, and B. Saltin, "In situ microdialysis of intramuscular prostaglandin and thromboxane in contracting skeletal muscle in humans," Acta Physiologica Scandinavica, vol. 171, no. 1, pp. 71-76, 2001.

[26] M. Dallaporta, E. Pecchi, S. Thirion, A. Jean, and J. D. Troadec, "Toward the management of inflammation: recent developments of mPGES-1 inhibitors," Recent Patents on CNS Drug Discovery, vol. 5, no. 1, pp. 70-80, 2010.

[27] T. Bachawaty, S. L. Washington, and S. W. Walsh, "Neutrophil expression of cyclooxygenase 2 in preeclampsia," Reproductive Sciences, vol. 17, no. 5, pp. 465-470, 2010.

[28] M. L. Novak, W. Billich, S. M. Smith et al., "COX-2 inhibitor reduces skeletal muscle hypertrophy in mice," American Journal of Physiology-Regulatory, Integrative and Comparative Physiology, vol. 296, no. 4, pp. R1132-R1139, 2009.

[29] M. Korotkova, S. B. Helmers, I. Loell et al., "Effects of immunosuppressive treatment on microsomal prostaglandin $\mathrm{E}$ synthase 1 and cyclooxygenases expression in muscle tissue of patients with polymyositis or dermatomyositis," Annals of the Rheumatic Diseases, vol. 67, no. 11, pp. 1596-1602, 2008.
[30] M. Korotkova and P. J. Jakobsson, "Microsomal prostaglandin e synthase-1 in rheumatic diseases," Frontiers in Pharmacology, vol. 1, p. 146, 2011.

[31] C. Blais Jr., A. Adam, D. Massicotte, and F. Péronnet, "Increase in blood bradykinin concentration after eccentric weight-training exercise in men," Journal of Applied Physiology, vol. 87, no. 3, pp. 1197-1201, 1999.

[32] H. Langberg, C. Bjørn, R. Boushel, Y. Hellsten, and M. Kjaer, "Exercise-induced increase in interstitial bradykinin and adenosine concentrations in skeletal muscle and peritendinous tissue in humans," Journal of Physiology, vol. 542, no. 3, pp. 977-983, 2002.

[33] M. Hamza, X. M. Wang, A. Adam et al., "Kinin B1 receptors contributes to acute pain following minor surgery in humans," Molecular Pain, vol. 6, p. 12, 2010.

[34] J. B. Su, "Different cross-talk sites between the reninangiotensin and the kallikrein-kinin systems," Journal of the Renin-Angiotensin-Aldosterone System, vol. 15, no. 4, pp. 319-328, 2014.

[35] R. Couture, M. Harrisson, R. M. Vianna, and F. Cloutier, "Kinin receptors in pain and inflammation," European Journal of Pharmacology, vol. 429, no. 1-3, pp. 161-176, 2001.

[36] S. Murase, E. Terazawa, F. Queme et al., "Bradykinin and nerve growth factor play pivotal roles in muscular mechanical hyperalgesia after exercise (delayed-onset muscle soreness)," Journal of Neuroscience, vol. 30, no. 10, pp. 3752-3761, 2010.

[37] O. A. Dina, P. G. Green, and J. D. Levine, "Role of interleukin6 in chronic muscle hyperalgesic priming," Neuroscience, vol. 152, no. 2, pp. 521-525, 2008.

[38] M. N. Manjavachi, E. M. Motta, D. M. Marotta, D. F. Leite, and J. B. Calixto, "Mechanisms involved in IL-6-induced muscular mechanical hyperalgesia in mice," Pain, vol. 151, no. 2, pp. 345-355, 2010. 


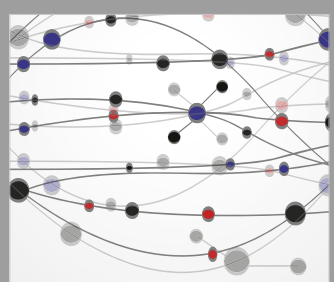

The Scientific World Journal
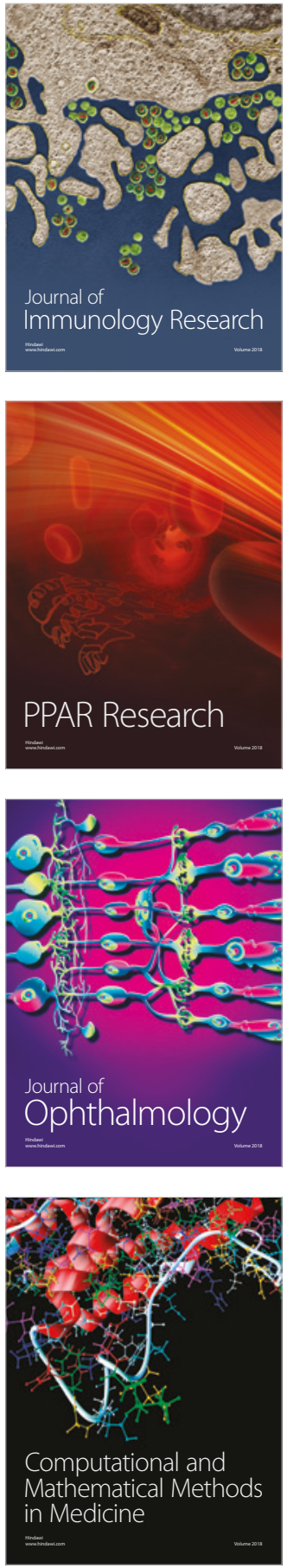

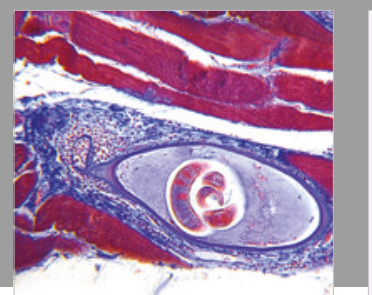

Gastroenterology Research and Practice

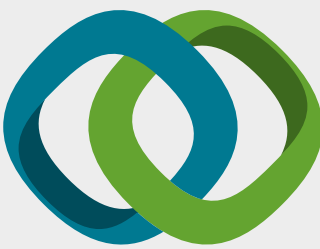

\section{Hindawi}

Submit your manuscripts at

www.hindawi.com
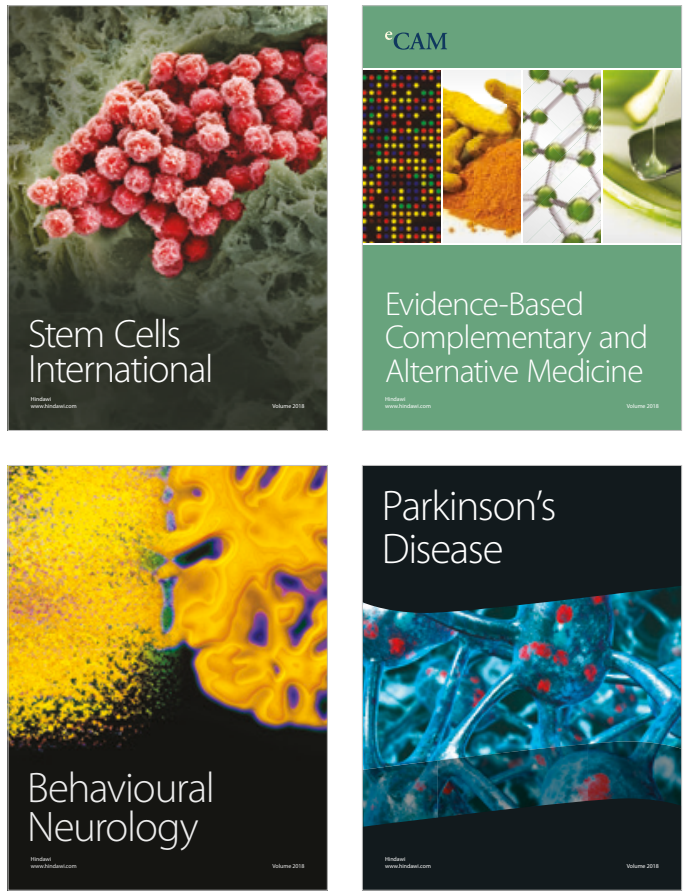

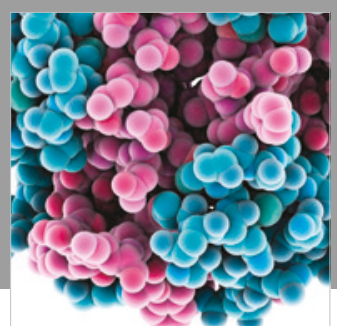

ournal of

Diabetes Research

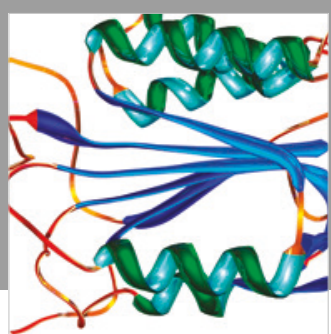

Disease Markers
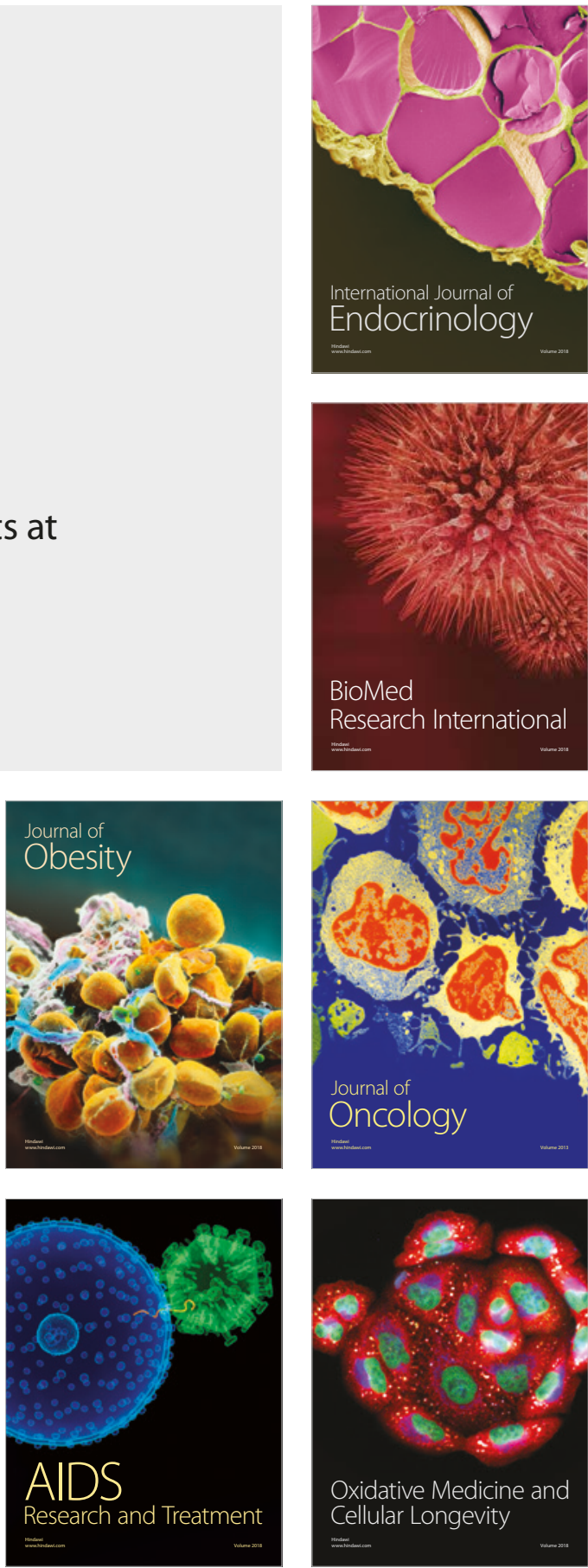